\title{
Investing in the Intellectual Capital of Albaha University, Saudi Arabia: The Concept and Mechanisms
}

\author{
Saeed S. Alghamdi, Mohamed E. Wagih, Abdulwahid S. Alzahrani, Mohamed A. Attia \\ Albaha University, Albaha, Saudi Arabia
}

\begin{abstract}
The determination of Saudi Arabia's government to develop universities able to contribute to knowledge-based economy provides the rationale for the newly founded Albaha University to enhance the investment in its Intellectual Capital (IC). This paper presents and analyzes the state of IC management concept at Albaha University, noting the benefits and the caveats to its adoption, and relating this to the internal function of the University, especially in the areas of strategy formulation and execution, teaching and research, and staff development. The paper suggests increasing attention and investment in IC and its adoption by the University to speed up a shift from fuzzy goals to measurable outcomes, in order to improve its efficiency and effectiveness, and to drive the University towards sustainable competitive advantage.
\end{abstract}

\section{Introduction}

The global transformation in IC in recent years has produced many new economic concepts that can be taken as criteria for evaluating institutions. This transformation has made it necessary for institutions and stakeholders to achieve "competitive advantage" viv-a-vis other institutions. Knowledge being the most important asset of universities and scientific research institutions, it is considered to be the key factor in achieving this sustainable competitive advantage [1]. While explicit knowledge can be captured and shared in the form of courses or books for self-reading, scientific formulae, and the like, and can be readily transmitted between individuals formally and systematically; tacit knowledge is only know by an individual and is difficult to communicate to the rest of an organization, hence difficult to capture [2].

Stewart [3] contextualized knowledge within a holistic concept termed Intellectual Capital (IC). He defined IC as being "the intellectual material of intangible assets including tacit knowledge, information, intellectual property, and experience that can be put to use to create wealth". IC is an investment pot with a sophisticated for sustainable competitive advantage for organizations [4]. Alhilali [5] stated that since the early nineties, recognition of the importance of IC began to overtake reliance on natural resources and fixed corporate assets to create wealth. In light of increasing competition between universities, and the need for new management mechanisms, and the desire of universities for more institutional autonomy, industrial, academic, and community relations, and the need for universities to become more transparent and accountable to its shareholders, necessitates increased investment in IC [6].

The term "Intellectual Capital" is claimed to have first appeared in an article "Genealogy of Ideas" written by E.W. Johnston in the Southern Literary Messenger [7]. However, Sullivan [8] stated the term first appeared in 1975, and Stewart tracked the first use of the term to G. R. Feiwel's "The Intellectual Capital of Michael Kalecki" (1975), in which he attributed the term to John Kenneth Galbraith, who in a letter to the economist Michael Kalecki in 1969 wrote "I wonder if you realize how much those of us in the world around have owed to the intellectual capital you have provided over these past decades". Sveiby [9] quotes Stewart, in his article Brain Power "How Intellectual Capital Is Becoming America's Most Valuable Asset" (June, 1991), as bringing IC firmly into the management agenda.

Albaha University, being an emerging modern institution founded by the royal decree No $9682 / \mathrm{mb}$ dated September 9th, 2005 with a mission to provide distinguished and comprehensive higher education, research, community service and lifelong learning environment through the utilisation of the available resources to ensure the best results. The University is faced with newer challenges and demands such as the need to be more relevant in its curriculum offerings and research endeavours, to be more resourceful and more results-oriented. This has led to ambivalent reactions on the part of the University, especially as being a public institution. While, on the one hand, the University wishes to jealously guard its autonomy, on the other hand, its increasing dependence on government funding is found less due to competition among increasing number of public universities in the system and other competing societal needs.

This situation has set up many dynamics, such as the need to improve their management and reporting systems, the need to be more creative and innovative and the need to show greater accountability and transparency towards their stakeholders. The IC framework has been recognised as the tool for meeting these challenges and achieve a greater satisfaction of societal needs. Through the IC framework adopted by Albaha University, traditional 
functions of the University of teaching and research are now compounded by the addition of outreach activities by which the University direct its expertise towards solving organisational and societal problems, thus leading to the creation of hybrid organisations, alliances between universities and firms and trilateral networks and directing their expertise towards solving organizational and societal problems in the region.

\section{The IC sub-domains}

At a university level, Antonella and Stefania [4] described briefly three main sub-domains of IC represented by human capital, structural/organizational capital associated with the organizational structure, and relational/Social capital associated with social relations. The Human Capital refers to the knowledge of researchers and nonscientific staff of universities, such as professors, researchers, $\mathrm{PhD}$ students and administrative staff. It is the knowledge, talent and the experiences of employees, which they take with them when they leave the organisation. However, the Structural or Organisational Capital comprises of the governance principles and modes, the organisational routines and procedures, culture systems, data bases and intellectual property. This represents all the nonhuman storehouses of knowledge; it is "what remains in the company when employees go home for the night". Relational/Social Capital is the totality of all activities and stable network of intra-organisational relationships; relations between universities and nonacademic partners, i.e. firms, non-for-profit organisations, public authorities, local government and society as a whole [6]. This is the relationship which the organisation has established within itself and with its customers, suppliers and other stakeholders.

Khalique, et al. [10] added another IC subdomain, the Technical Capital, which is knowledge related to access, use of innovation of production techniques and product technology. In the context of the university, technological capital relates to the use of technologies in the teaching/learning and research processes and IT. Moreover, Mitroff and Denton [11] considered spirituality a component of IC, adding Spiritual Capital as sub-domain of IC that consists of power, influence, spirit and knowledge which can be gained through religion. So, the dimensions of spiritual capital can be the intangible knowledge, faith and emotion embedded in the minds of individuals and in the heart of the organisation which includes vision, direction, guidance, principles, values, culture, happiness, forgiveness, kindness, integrity, empathy and honesty. Despite in predominantly Muslim counties, and specifically Saudi Arabia, spiritual capital is significantly important, it is together with technical capital are imbedded in the three main sub-domain of IC.
Figure (1) illustrates the relationship between IC main sub-domains, where it is clear that human capital is the driving force of the system and the power behind building the organizational capital. The relational capital is the defining element on which the IC system relies. Within the context of relational capital, human capital is a critical component, being the essence of internal and external relationships capital. As such, the components of the IC system are in reciprocal relationship with a built-in feedback mechanism [12].

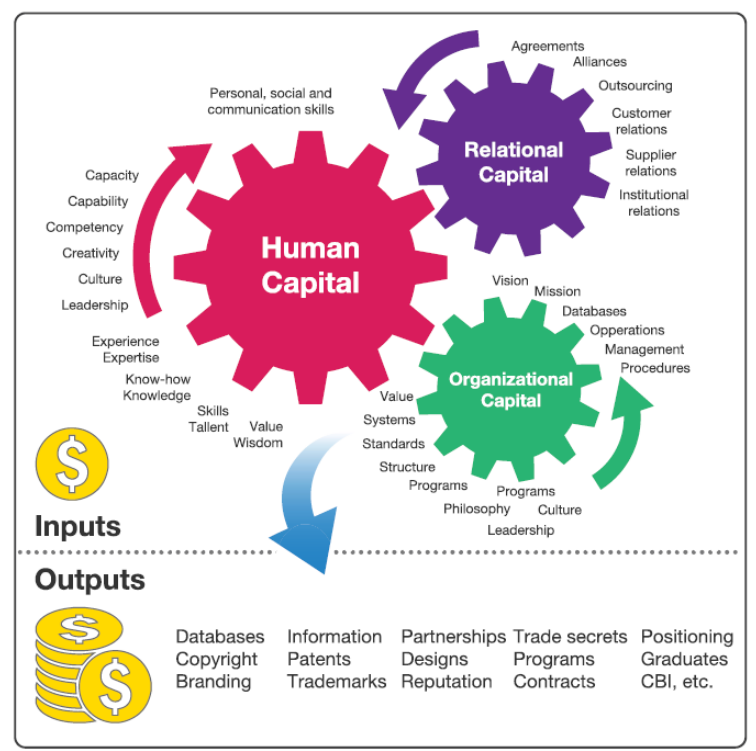

Figure 1. The interaction between IC sub-domains

\section{Universities' role in the knowledge- based economy}

There is a general consensus on the conviction that the intellectual intangible assets (IC) is the foundation of knowledge-based economy, wealth and economic growth [13]. Foray [14] indicated that in the knowledge-based economy, the contribution of intangible assets (IC) is much larger than traditional tangible assets to enhance organizational value and performance. As such, and in light of increasing competition between universities, and the need for new management mechanisms, and the desire of universities for more institutional autonomy, industrial, academic, and community relations, and the need for universities to become more transparent and accountable to its shareholders, makes it necessary for universities and academic and research institutions to activate the investment in their IC [4], [6].

\section{Characteristics of IC}

IC has been characterized of being non-financial and non-visible assets which do not have units of measurement, such as monetary units in the balance 
sheet, and are closely linked to intangible knowledge and experience from the knowledge assets of researchers, faculty and staff members, and provide better opportunities for universities to achieve the desired success, but constitute a large degree of risk on the university and its customers because knowledge has no specific standard or measurement units. Knowledge is considered debt items, because they are borrowed from researchers and faculty and staff members, rather than being fixed assets, as universities do not have complete control over this knowledge that develop from an accumulation of a large number of events and investments over a long period of time, and suspected with ethical concerns or ethical considerations as if it is the knowledge of human beings is part of the balance sheet and evaluate individuals at a price as another form of capital; and due to the lack of a unified methodology or a fixed opinion on how to measure IC, it is difficult to reach a consensus around it [15].

\subsection{Indicators of Saudi's economy turning to knowledge economy}

The impetus to development in Saudi Arabia is properly anchored on developing the IC of the nation, with the universities playing a vanguard role [16]. The educational sector has experienced a remarkable injection of funding in recent times, signalling the intention to make IC the foundation of a sustainable economy. In less than a century, there has seen a significant growth in the establishment of many educational departments and institutions that cater for different sectors of the Saudi communities which have been supported by suitable policies, financing and multiple incentives, and the country slowly moved away from the agricultural economy in rural areas to rely on the oil commodity, and towards becoming a developed education and knowledge seekers. The era of King Abdullah has been hailed as the "golden age of learning for Saudi Arabia" [16], as investment in education has increased markedly from $\$ 28.12$ billion in 2008 to $\$ 32.62$ billion in 2009 to $\$ 36.63$ billion in 2010 to $\$ 40.10$ billion in 2011 and to the highest ever level of $\$ 54.54$ billion in 2012 . Thus, during the five-year period, the budget in education has almost doubled [16].

According to the Report of the International Association of Universities [17], the Kingdom of Saudi Arabia has about 64 universities and academic institutes offering scientific degrees. In 2012, His Royal Highness, the late King Abdullah, opened a number of universities and educational cities, which cost the state 21.79 billion dollars to build. The report went on to say that King Abdullah has established a grant program in 2005 at a cost of $\$ 2.4$ billion annually. Under this program, 180000 Saudi students, male and female, managed nearly to pursue higher education in about 500 international university, forcing the country to be "an incubator for education, science and technology" in the foreseeable future. A realization of this, is the establishment of many leading educational institutions such as the King Abdullah University of Science and Technology (KAUST), which opened in 2007 at a cost of ten billion Saudi Riyals. This is the first research university at a graduate level of its kind in the world. KAUST represents a vital step in the transition of the Kingdom to the knowledge-based society, and to give the Saudis the opportunity to gain access to the most advanced research and researchers in the world, and to enable the Kingdom to take advantage of countries excel in the art, science and technology, which have the potential to have a profound effect on the country's economic development and quality of life. During the past four years of management, KAUST directed its research towards important political, economic and social reforms, which led to unprecedented positive changes in the Kingdom, especially in seeing the country to play a leading regional and global role, which led to a remarkable rise in the country global competitiveness level based on Competitiveness Report of the World Economic Forum [18].

There is no doubt that these universities and scientific institutions would be, like their counterparts in other parts of the world, facing enormous challenges and expectations, which requires their prudent management to develop and invest in their IC to fill the gap in the knowledge to the extent to which they can be relied upon to take the Kingdom of Saudi Arabia to the knowledge economy it is looking for itself in the new millennium. For this, the development of the state economy to a knowledge-based economy led to the interest of researchers, practitioners, academics, investors, and the governments to focus on investment in optimizing IC of universities and scientific research institutions in the country.

\subsection{Measuring and reporting IC in universities}

Experimentation with IC has taken place at meso (communities, industries) and at macro levels (cities, regions and nations), with the World Bank sponsoring some conferences on this issue in 20052007, and attempts have been made to measure IC at country level in countries such as Sweden, Israel, and the Arab region [19]. At the micro-level, governments of developed countries (UK, Australia, USA and Canada) and later some European countries and African countries demanded that their universities justify their existence through the measurement and reporting of IC. Sanchez et al. [6] provided case studies of IC measuring and reporting in universities at national, multinational and regional levels. Below is a summary of their main findings:

1. IC measurement and reporting were Initiated by supra-education bodies, such as the Ministry of 
Education or by the government itself, backed by Acts of Parliament.

2. Usually, task forces were set up to implement and monitor the process.

3. There are variations in the measurement and reporting models used.

4. The institutions all face the methodological problems of measuring non-physical processes and outputs

5. Some approached the exercise using trial and error approach

6. Some of the problems unearthed relate to practical questions such as how to collect the data needed, who should be responsible for data gathering and how frequently the IC report should be [20].

7. Some universities experience barriers to the introduction and management of IC models, among which are the following:

- fear of measurement and new systems,

- lack of understanding,

- lack of meaningful employee involvement,

- lack of common definitions of terms and IC indicator,

- vision and strategy poorly defined and understood.

8. Moreover, Antonella and Stefania [4] suggest building greater awareness among the senior academics occupying management positions at universities, to create an ad hoc IC measurement task force, introduce IC measurement methodologies which should be timely implemented and published.

9. Nevertheless, almost all of the reviewers are of the view that IC in universities should be measured as most agree that it is "Better to be roughly right than precisely wrong".

10. All agreed that IC reporting has both internal and external benefits. Internally, an IC report can facilitate management decisions by improving understanding of the university's activities and goals, by identifying intangible resources and capabilities and by improving investments and capital allocation. Externally, it helps to improve transparency with the society as a whole and to attract new employees, partners and collaborators [20], [21].

\subsection{The status of $I C$ in Albaha University}

Albaha University conducted a study to assess its scientific research outputs in the light of the University's vision with respect to IC. A workshop on the subject was held in 2015, attended by the University administration. Action plans regarding knowledge management practices at Albaha University were developed which considered the university's IC standing and the relationship between IC and strategic goals of the University. Further consideration of the subject will occur with the hosting of an international conference on IC, scheduled for 2016. Anticipate benefits of this conference include a consolidation of the concept of IC and the input and engagement of local and international IC expertise. This will enhance the Strategic Plan of the University and stimulate broad support from faculty members, partners and societal institutions.

\subsection{Why Albaha University measures its IC}

Albaha University is committed to its new focus on intangible assets, where studies have demonstrated a positive and significant relationship between IC and university cognitive performance and productivity [22]. The University's primary output, or "product", is knowledge, arising from original research and publications,, along with, of course, graduates. The University's interest in IC, therefore, is natural and consistent with its raison d'etre.

\section{Research attributing to IC in Albaha University}

In the recent years (2011/2012 - 2014/2015), Albaha University witnessed an evolution of investing in its IC through maximizing research funding, and enhancements to faculty expertise. The progress achieved in this field is due to a number of factors, including the belief of His Royal Highness, Prince Mishari bin Saud bin Abdul Aziz, the Prince of Albaha region, along with the University leadership, in the IC capacity of the University and the role of research in achieving economic and social development goals of the region. Out of the University's interest to achieve comparative advantage by better manage its IC resources, the office of the VP for Graduate Studies and Scientific Research encourages faculty members to engage in research with innovative ideas that suit the nature of the region. To this end, it has promised to provide adequate funding to implement them in order to best serve the region.

Meanwhile, the University emphasized the necessity to establish distinct research labs and centres of excellence, by providing the necessary equipment and by supporting a number of research projects that serve the objectives of these laboratories. In addition, the University linked research funding with the ability of faculties to publish their findings in international, refereed, indexed journals of impact, not in isolation of the community, in order to effect a greater degree of community participation and engagement.

The statistical analysis of research activities illustrates the keenness of the University to make a qualitative and quantitative leap in scientific research that serves community needs, while achieving local and international competitiveness. 


\subsection{Albaha University research by colleges}

Table 1 presents the distribution of research projects by college during the academic year $2012 / 2013$. It demonstrates a disparity between colleges in the number of projects submitted. The total of 68 projects were submitted during that year, of which $53(78.1 \%)$ projects were accepted for funding. This is significantly higher than a total number of four projects submitted for the academic year 2011/2012, and six projects in 2010/2011, illustrating a clear evolution in the culture of scientific research. Investigation of the reasons for the increase in the total number of projects over the three academic years, and the disparity in the number of projects among colleges in 2012/2013, was necessary for the university to develop appropriate solutions and programs to stimulate scientific research in all colleges.

On the one hand, the significant increase is believed to be due to encouragement of faculties to undertake local or regional research, and to facilitate a better understanding of the impediments facing scientific research. In addition, His Royal Highness the Prince of the region, Prince Mishari bin Saud bin Abdul Aziz, continued to encourage the University to mobilize its IC toward identified regional development priorities.

On the other hand, the reasons for disparity between colleges in the number of projects submitted varied by the characteristics defining each college. For example, the Faculty of Education was the highest in the number of projects, where the college submitted 12 projects, of which 11 projects $(91.7 \%)$ were funded. The accepted projects constituted $20.2 \%$ of the total projects accepted. The reason for the high number of projects submitted is believed to be that the Faculty of Education has more than 80 faculty members. Also, projects were mostly descriptive in nature, with a relatively low budget of less than SAR 60,000, allowing for high acceptance numbers. In addition, most research ideas submitted were relevant to a number of pressing educational issues and, as such, would have tangible impacts in the region.

The College of Administrative and Financial Sciences parallels the College of Education for projects submitted, where 10 research projects were accepted for funding, and constituting $18.4 \%$ of the total University number of projects accepted. The high number of research projects submitted by the college is believed to be due to the strong relationship between the capacity of the college and the economic and social goals of University and the region. Additionally, the College has leaders who are keen to raise the level of research, in addition to the existence of an appropriate number of interested faculty members. Because research in the area does not usually require laboratories or expensive equipment, there was an opportunity to support a greater number of projects.
Table 1. Distribution of research projects by college in Albaha University during the academic year 2012/2013

\begin{tabular}{|c|c|c|c|c|c|}
\hline College & 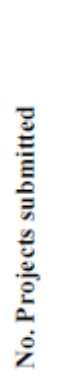 & 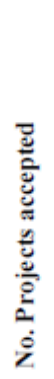 & 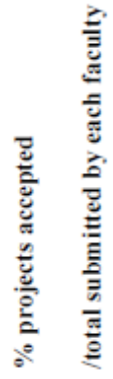 & 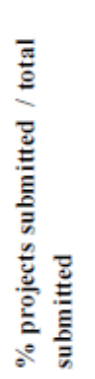 & 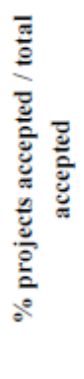 \\
\hline Science & 9 & 8 & 88.9 & 13.2 & 3 \\
\hline Engineering & 7 & 6 & 85.7 & 10.3 & 11.3 \\
\hline Medicine & 2 & 2 & 100.0 & 2.9 & 3.8 \\
\hline $\begin{array}{l}\text { Applied Medical } \\
\text { Sciences }\end{array}$ & 3 & 3 & 100.0 & 4.4 & 5.7 \\
\hline $\begin{array}{l}\text { Clinical } \\
\text { Pharmacy }\end{array}$ & 6 & 3 & 50.0 & 8.8 & 5.7 \\
\hline $\begin{array}{l}\text { Administrati-ve } \\
\& \text { Financial } \\
\text { Sciences }\end{array}$ & 12 & 10 & 83.3 & 17.6 & 18.9 \\
\hline $\begin{array}{l}\text { Arts and } \\
\text { Humanity }\end{array}$ & 2 & 1 & 50.0 & 2.9 & 1.9 \\
\hline Education & 12 & 11 & 91.7 & 17.6 & 20.8 \\
\hline $\begin{array}{l}\text { Sciences and Arts } \\
\text { (Mekhwa) }\end{array}$ & 7 & 3 & 42.9 & 10.3 & 5.7 \\
\hline $\begin{array}{l}\text { Sciences and Arts } \\
\text { (Mandaq) }\end{array}$ & 2 & 2 & 100.0 & 2.9 & 3.8 \\
\hline $\begin{array}{l}\text { Sciences and Arts } \\
\text { (Balgorishi) }\end{array}$ & 6 & 4 & 66.7 & 8.8 & 7.5 \\
\hline $\begin{array}{l}\text { Sciences and Arts } \\
\text { (Quilwa) }\end{array}$ & 0 & 0 & 0.0 & 0.0 & 0.0 \\
\hline $\begin{array}{l}\text { Computer } \\
\text { Science and IT }\end{array}$ & 0 & 0 & 0.0 & 0.0 & 0.0 \\
\hline
\end{tabular}

The colleges of Science, Engineering, Sciences and Arts (Balgorishi), which submitted 9, 7 and 6 projects, are shown in Table 1. Of these, 8, 6 and 4, respectively, were accepted for funding. Contributing such a relatively moderate number of research projects may be explained by the fact that laboratories and facilities in these colleges are well developed, along with the existence of welldeveloped research groups, and that the research projects in these colleges could be carried out in stages, leading to spreading the high budgets over a number of years.

Reasons for the weak participation in scientific research by the College of Applied Medical 
Sciences, which submitted six projects, only three of which were accepted for funding, are thought to be the low number of faculty members, the relocation of the college to other premises, and the high teaching load of staff. The more recently established colleges, such as the College of Sciences and Arts and the College of Computer Sciences and Information Technology, did not contribute any research proposals that year. This may be due to the state of the educational and academic stability of these colleges. However, while noted that the College of Clinical Pharmacy is a newly established college, faculties submitted six projects, of which three $(50 \%)$ were accepted for funding. This is attributed to the international connection of faculties, the institution's centres of excellence and research hubs, as well as the appreciation of staff of the fauna and flora diversity in the region, which hold promise in the pharmaceutical field.

\subsection{Albaha University research by themes}

Table 2 shows submitted research projects grouped in three fields/themes: basic and engineering sciences, health and medical sciences, and humanities, social, and educational sciences.

Table 2. Distribution of research projects by field at Albaha University during the academic year 2012/2013

\begin{tabular}{|c|c|c|c|c|c|}
\hline Field & 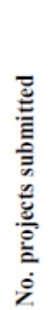 & 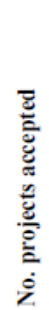 & 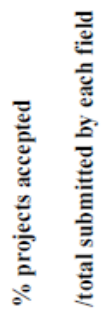 & 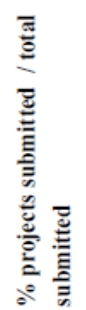 & 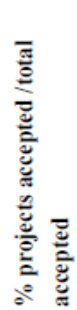 \\
\hline $\begin{array}{l}\text { Basic and } \\
\text { Engineeri } \\
\text { ng } \\
\text { Sciences }\end{array}$ & 21 & 15 & 71.4 & 30.9 & 28.3 \\
\hline $\begin{array}{l}\text { Health } \\
\text { and } \\
\text { Medical } \\
\text { Sciences }\end{array}$ & 15 & 12 & 80.0 & 22.1 & 22.6 \\
\hline $\begin{array}{l}\text { Humaniti } \\
\text { es, Social, } \\
\text { and } \\
\text { Education } \\
\text { al } \\
\text { Sciences }\end{array}$ & 32 & 26 & 81.3 & 47.1 & 49.1 \\
\hline TOTAL & 68 & 53 & 77.9 & 100 & 100 \\
\hline
\end{tabular}

The greatest number of projects was submitted by humanities, social, and educational sciences colleges, with a total of 32 projects submitted, constituting $47.1 \%$ of the total number submitted in the academic year $2012 / 2013$. Of these projects, 26 were accepted for funding constituting $81.3 \%$ of the total submitted. The accepted projects of this field represent $49.1 \%$ of the total accepted from all three fields.

The number of research projects submitted in the disciplines of basic sciences and engineering research was 21 comprising $30.9 \%$ of the total research projects submitted. Only 15 projects were accepted for funding, representing $71.4 \%$ of projects submitted in this field. This was followed by the projects submitted by health and medical sciences colleges, which amounted to 15 projects, comprising $22.1 \%$ of the total research projects submitted by all three fields. Only 12 research projects were accepted for funding, representing $80 \%$ of the total projects submitted by this group, and $22.6 \%$ of the total accepted projects from all three fields.

This is believed to be due to the suitability of research projects submitted by the humanities, social, and educational sciences colleges to the total University budget allocated for research, and the projects in this field were more directly related to the immediate needs of the University and the community. In addition, the relative rise in the number of projects submitted from the basic and engineering sciences is associated with the general trend in the University towards acceptance of projects concerned with the purchase of equipment and laboratory equipment that will enable the University to develop distinct research facilities.

\subsection{Staff, students, and consultants role in research}

Participating in some research projects, are 25 technicians and 54 administrators, giving them an opportunity to improve their research skills. Also participating are 24 graduate students and 68 undergraduate students, giving them an opportunity to relate research to the "real world" after graduation, and to improve their research skills and expertise. The participation of a small number of students in research, whether graduate or undergraduate, may be due to the nature of the research work. Also, 19 consultants from inside and outside the Kingdom participated in the research projects. The consultants were hired in less than one-third of research projects due problems justifying their utilization, from both home and abroad.

\subsection{Research budgets of Albaha University}

Normally, research budgets requested by researchers are reviewed by several bodies from within the University. In the absence of external funding sources, the reviewers found a sizable gap between what was requested and what was available. Meanwhile, the University tried to provide funding for as many projects as possible, on the basis of prioritization. Table 3 shows the allocated budget of accepted research projects of the academic years $2011 / 2012$ to $2014 / 2015$. 
As can be seen from Table 4, there is a clear evolution in the budget for scientific research during the four academic years' period. In 2011/2012 year, the total allocated budget was SAR 2.44 million as funding for six research projects with an average of SAR 407,000 per project. This resulted in the reluctance of faculties to take the trouble of applying for research funds, and an ensuing decrease in the budget for scientific research in the following academic year. That year witnessed only SAR 201,000 for funding of four projects, averaging SAR 50,000 per project.

Table 3. Budget of accepted research projects of the academic years 2011/2012 to 2014/2015

\begin{tabular}{|c|c|c|c|c|}
\hline $\begin{array}{l}\text { Academic } \\
\text { Year }\end{array}$ & 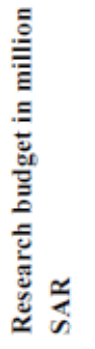 & 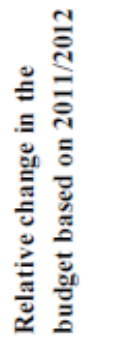 & 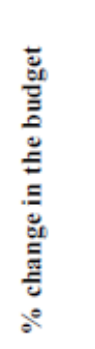 & 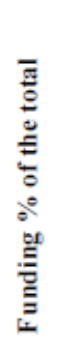 \\
\hline $2011 / 2012$ & 2.439 & - & -- & 28.35 \\
\hline $2012 / 2013$ & 0.201 & -2.238 & -91.76 & 2.34 \\
\hline $2013 / 2014$ & 4.464 & +4.263 & 2120.9 & 51.88 \\
\hline $2014 / 2015$ & 1.500 & -2.964 & -66.40 & 17.43 \\
\hline TOTAL & 8.604 & & & 100 \\
\hline
\end{tabular}

There was a significant increase in the research fund during the academic year 2013/2014 reaching SAR 4.5 million. The number of funded projects increased to 53 projects, with an average of SAR 85,000 per project. The increase in allocation of research funds in that academic year's budget was ostensibly due to a change in leadership at the level of VP for Graduate Studies and Scientific Research.. A new era ensued, marked by visionary leadership and management of the University IC, to the betterment of the University, the region, and the Kingdom. The highest degree of trust was experienced between faculties and its leadership, and extensive submissions of research proposals resulted, in 2014/2015. The University held a number of scientific events related to the dissemination of research. Apart from the knowledge dissemination process, the purpose was to familiarize them with the IC concept, as well as to improve the submission process of projects.

The research budget in the year 2014/2015 is expected to reach SAR 6.0 million. The Standing Committee for Scientific Research aimed to accept a greater number of research projects, after subjecting projects to the following IC measures:
1. Projects should be applied or developmental in nature.

2. Projects must be built on an original and intelligent idea with an obvious objective to achieve technological innovation in connection with external stakeholders.

3. Ensure that every proposal is co-supported by community, industry, government, and private research beneficiary partners.

\subsection{Promoting IC culture in Albaha University}

Albaha University through the office of the VP for Graduate Studies and Scientific Research is trying its best to make full use of scientific research in support of development efforts in Albaha region in particular, and Saudi Arabia generally. Scientific research in Albaha University is not intended to produce a number of published scientific research papers in advanced journals at local or global levels, but to market research results, diverting thoughts and ideas to products serving the development sought by the community.

Table 4. Analysis of accepted research projects of the academic years 2011/2012 to 2014/2015

\begin{tabular}{|c|c|c|c|c|}
\hline $\begin{array}{l}\text { Academic } \\
\text { Year }\end{array}$ & 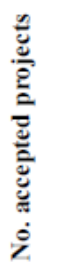 & 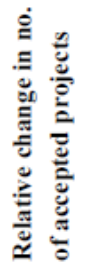 & 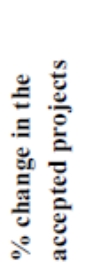 & 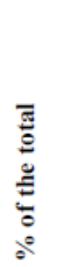 \\
\hline $2011 / 2012$ & 6 & -- & -- & 4.20 \\
\hline $2012 / 2013$ & 4 & -2 & -33.33 & 2.80 \\
\hline $2013 / 2014$ & 53 & +51 & +1275.0 & 37.06 \\
\hline $2014 / 2015$ & 80 & +27 & +50.94 & 55.94 \\
\hline TOTAL & 143 & & & 100 \\
\hline
\end{tabular}

On this basis, the University placed emphasis on the importance of optimal investment in its IC. Within this context, a number of workshops and scientific events were held or are being planned to guide researchers to produce scientific research of impact on society, as well as to make the most of all material and human resources the University provides to achieve this objective. These activities and events include:

1. The First Forum for Scientific Research in the University was held during 17-18/03/2014 to discuss issues related to the financing of scientific research at Albaha University, as well as to familiarize faculties with grant funding procedures. It was within these measures that the research has the impact on the University and the community, 
meaning that there is a distinct return from scientific research to serve the goals of the overall development desired.

2. A Workshop on "the Mechanisms of Achieving Quality Performance in Light of Emerging Universities' Mutual Experiences" was held on 1$2 / 04 / 2014$

3. The First Workshop of the Research Chair on Olive Research and Rehabilitation in Albaha region, named after Sheikh Saeed Bin Ali Alanqari, and carrying the slogan "Research Chair and Community Partnership", was held on 17/02/2015. The Workshop was attended by almost a hundred community farmers, as well as academics, government officials, and NGOs. The main objective of this Workshop is to achieve effective community partnership, to achieve the development goals sought by Albaha community in the field of agricultural development and, in particular, the development of olive cultivation in the region, in order to achieve a paradigm shift required in this field, taking in consideration that the region is qualified as distinct investment site suitable for olive cultivation. This is a practical application of investment in IC.

4. Recording academic activities and scientific meetings in academic departments as well as public research activities with participation of all interested parties to serve the University scientific research began on 22/05/2015, thus contributing to the formation of research groups in interdisciplinary research.

5. A scientific Workshop was held on 10/03/2015 in the presence of a large number of university leaders and faculty members amounted to 225 participants. The Workshop addressed measuring scientific research output of the University since its inception on 09/09/2005., under the slogan "The Optimum Investment in IC of Albaha University"; as part of a research project entitled "outputs of scientific research in Albaha University, factors influencing the research productivity of the University, and ways to develop it".

6. A Workshop entitled "The Role of Interdisciplinary Scientific Research in the Service of Society" on 17/03/2015, as a part of a research project funded by the Scientific Research funded by Albaha University entitled "Classification for the Formation of Tissues and Cells Using Images Analysis". The Workshop was attended by a number of third parties represented the Health Department in Albaha region, and extensive presence of university faculties.

7. The First International Conference of the College of Education was held during the period from 12-15 /04/2015 under the slogan "Education, Future Prospects". School teachers and faculties from inside and outside the Kingdom participated in the Conference with research papers and workshops, addressing a large number of issues and problems related to education at the local and global level, as well as creating a number of outstanding expertise in the field of education and administration in order to achieve the desired development in this important field.

8. Participation of University faculties in more than 15 conference, seminars and workshops in a range of disciplines, held outside the Kingdom, and eight participations during June 2015 are being processed for University faculties.

9. Planning the International Conference/Forum on IC in the middle of 2016 with participation of a number of speakers locally and globally.

10. Planning the First International Conference on Olive in Albaha and Saudi Arabia, which will be held at the end of 2016 under the slogan "Olive hope and reality", as an activity under the research chair of Sheikh Said bin Ali Alanqari. The Conference targets farmers, government departments, academics from inside and outside the Kingdom.

\section{Conclusion}

This paper clarified the nature of IC, its properties, and relevance to the needs and objectives of universities, especially the emerging universities represented by Albaha University. The paper also pointed out the challenges faced by the University, and the need to monitor and evaluate the IC of the University in line with the country's pace towards the knowledge-based economy, and the need to attract and retain highly qualified knowledge workers.

\section{References}

[1] R. M. Grant, (1991). A Resource-Based Theory of Competitive Advantage: Implications for strategy formulation. California Management Journal, pp 33.

[2] S.E. Seibert, M.L. Kraimer, and R.C. Liden, (2001). "A social capital theory of career success", Academy of Management Journal, 44 (2): 219-38.

[3] T. A. Stewart, (1999). Interview: Tom Stewart on Intellectual Capital. Retrieved 20 July 2003, from http://www.it-consultancy.com/extern/stewart-ic.html

[4] S. Antonella, and V. Stefania, (2007). Comparing experiences in reporting intellectual capital in universities. https://ideas.repec.org/a/ora/journl/v1y2011i2p618624.html

[5] A.A. Alhilali, (2011). Management of IC, its measurement, and development as part of the knowledge management in higher education institutions. J. Qualitative Edu. Res. No. 22. July 2011.

[6] M. B. Sanchez, S. Elena, and R. Castrillo, (2009). IC dynamics in universities: a reporting model. J. Intellectual Capital, 10(2): 307-3241.

[7] Southern Literary Messenger, Vol. VIII No. IX (1842). http://longstreet.typepad.com/thesciencebookstore/2010/12 /the-origin-of-the-term-intellectual-capital-1842.html 
[8] P. H. Sullivan, (2000). Value-driven Intellectual Capital; How to convert intangible corporate assets into market Value. Retrieved 3 August 2003, 2003, from http://www.sveiby.com/articles/icmmovement.htm

[9] K. E. Sveiby, (1998). Intellectual capital and knowledge management. Retrieved 2 August 2003, from http://www.sveiby.com/articles/IntellectualCapital.html

[10] M. Khalique, J. A N. Shaari, and A. H. Isa, (2011). IC and its major components. International Journal of Current Research, 3(6): 343-347.

[11] I. A. Mitroff, and E. A. Denton, (1999). A spiritual audit of corporate America: A hard look at spirituality, religion, and values in the workplace. San Francisco: Jossey-Bass/Pfeiffer

[12] R. Petty and J. Guthrie, (2000). Intellectual capital literature review: Measurement, reporting and management. J. Intellectual Capital, 1(2): 155-176.

[13] B. Lev, (2001). Intangibles: Management, Measurement and Reporting. The Brookings Institution, Washington, DC.

[14] D. Foray, (2004). Economics of knowledge. MIT Press. Cambridge.

[15] A. Fazlagic, (2005). Measuring the IC of a university. Proc. Conference on Trends in the management of human resources in higher education, 25 and 26 August 2005, OECD Headquarters, Paris.

[16] Arab News, (2013). Saudi Arabia's "Golden Age of Learning" under King Abdullah: Exclusive Interview, 5-6.

[17] IAU, (2014). Annual Report of the International Association of Universities 2014. Retrieved 22 August 2015, from http://www.iau-aiu.net/sites/all/files/IAUANNUAL-REPORT-2014-EN-WEB.pdf

[18] WEF, (2013). The Global Competitiveness Report 2013- 2014. Geneva: World Economic Forum.

[19] N. Bontis, (2004). National IC index. A United Nations initiative for the Arab region. J. Intellectual Capital, 5(1): 13-39.

[20] M. P. Sanchez, R. Castrillo, and S. Elena, (2006). IC management and reporting in universities: usefulness, comparability and Diffusion, Best practices in data gathering and analysis from the Autonomous University of Madrid. Paper presented at the International Conference on Science, Technology and Innovation Indicators. History and new perspectives. Lugano. Internet device: http://www.ticinoricerca.ch/conference/full_pdf/sanchez_1 ugano.pdf

[21] European Commission, (2006). RICARDIS (Reporting IC to augment research, development and innovation in SMEs)", Brussels. Internet device: http://ec.europa.eu/invest-in-research/pdf/download_en/ 2006-2977_web1.pdf

[22] Y. C. Huang and Y. J. Wu, (2010). IC and knowledge productivity: the Taiwan Biotech Industry, Management Decision, 48 (4): 580-599. 